\title{
Commentary: Off-pump mitral repair-Augmenting the future
}

\author{
Ronald D. Baxter, MD, John J. Squiers, MD, and J. Michael DiMaio, MD
}

\author{
From the Department of Cardiothoracic Surgery, The Heart Hospital Baylor Plano, Plano, Tex. \\ Disclosures: Authors have nothing to disclose with regard to commercial support. \\ Received for publication March 13, 2019; accepted for publication March 14, 2019; available ahead of print April \\ $16,2019$. \\ Address for reprints: J. Michael DiMaio, MD, The Heart Hospital Baylor Plano, 1100 Allied Dr, Plano, TX 75093 \\ (E-mail: jmdimaio@yahoo.com). \\ J Thorac Cardiovasc Surg 2019;158:e137 \\ 0022-5223/\$36.00 \\ Copyright (C) 2019 Published by Elsevier Inc. on behalf of The American Association for Thoracic Surgery \\ https://doi.org/10.1016/j.jtcvs.2019.03.051
}

Functional mitral valve regurgitation continues to greatly increase morbidity and mortality of patients with ischemic cardiac disease. Medical management of mitral regurgitation for this condition can be effective when no other options exist; however, surgical treatment of mitral valve dysfunction for reduction of valvular regurgitation has been shown to increase both quality of life and overall survival in these patients. ${ }^{1}$ Operative interventions in this patient population continue to be challenging as a result of decreased physiologic reserve and increased risk of perioperative complications and mortality. In this issue of the

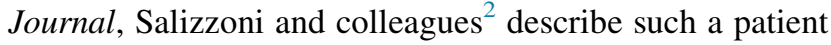
in their case report. Repair of this patient's mitral valve would be complex because of its severe dysfunction and his challenging underlying comorbidities. Traditionally, surgical intervention for this patient could be considered prohibitively risky by many centers. The innovative technique described in this case report, however, offers an interesting approach to this problem.

Emerging technologies allow mitral annuloplasty, leaflet edge fixation, and even leaflet tethering in a beating heart without the need for bypass. The most recent innovation-leaflet fixation-has shown great promise in this setting. ${ }^{3}$ Currently, however, these options are limited by mitral leaflet and annulus anatomy. Furthermore, a combination of surgical repair options is often needed in this population because of the complex nature of mitral valve anatomy. The technique described in this report, which allowed adequate repair of the mitral valve by leaflet augmentation on a beating heart free of cardiopulmonary bypass, has never been previously described. Proper use of mitral augmentation patches can be challenging for even experienced cardiac surgeons in an on-pump, cardiac arrest scenario. The willingness of the surgeons even to consider performing this procedure on a beating heart is an example of the mindset that has pushed cardiac surgery forward in patient care and technical advancement.

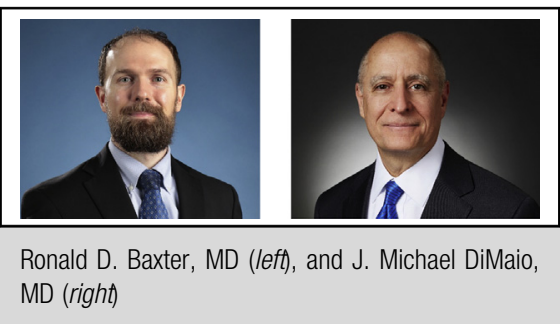

Central Message

Institution of advanced mitral valve treatmen modalities has greatly affected care for severe mitral disease. Ongoing development of new techniques is needed to expand treatment options for patients.

See Article page e133.
The patient described in this case report, a 76-year-old man with significant congestive heart failure and history of multiple coronary artery bypass, is also to be commended. Although he was at high risk in undergoing surgical intervention, he was willing to proceed with a procedure that had never before been performed in a human being. Not only does this reflect his strong desire to alleviate his lifealtering symptoms, it also highlights his faith in the surgical team caring for him. His consent to proceed was an essential part in pioneering these new care techniques for other patients with similar pathology.

This report describes an innovative surgical technique that may warrant further investigation as we progress from traditional valvular augmentation procedures to minimally invasive techniques. Ongoing development may lead to a method of augmenting valvular tissue through completely endovascular methods and further increase available options for high-risk patients to receive optimal cardiac repair.

\section{References}

1. Vesely MR, Benitez RM, Robinson SW, Collins JA, Dawood MY, Gammie JS Surgical and transcatheter mitral valve repair for severe chronic mitral regurgitation: a review of clinical indications and patient assessment. J Am Heart Assoc. 2015;4:e002424.

2. Salizzoni S, Marro M, Vairo A, Grosso Marra W, Speziali G, Rinaldi M Transventricular off-pump anterior mitral leaflet augmentation: first in human. J Thorac Cardiovasc Surg. 2019;158:e133-5.

3. Stone GW, Lindenfeld J, Abraham WT, Kar S, Lim DS, Mishell JM, et al; COAPT Investigators. Transcatheter mitral-valve repair in patients with heart failure. N Engl J Med. 2018;379:2307-18. 